\title{
Analysis of right heart flow patterns in repaired Tetralogy of Fallot with 4D flow-sensitive MRI
}

\author{
Christopher J Francois*', Shardha Srinivasan, Benjamin R Landgraf, Eric Niespodzany, Oliver Wieben, \\ Alex Frydrychowicz
}

From 2011 SCMR/Euro CMR Joint Scientific Sessions

Nice, France. 3-6 February 2011

\section{Introduction}

Cardiac MRI (CMR) is used to follow patients after TOF repair to assess pulmonary regurgitation (PR), pulmonary stenosis (PS) and right ventricular (RV) function. 4D flow-sensitive MRI techniques enable visualization of complex flow patterns [1],[2]. With the ability to simultaneously acquire morphology and hemodynamics for visualization and quantification, they may improve evaluation of functional outcomes following surgery for complex CHD.

\section{Purpose}

Analyze flow patterns in superior vena cava (SVC), inferior vena cava (IVC), right atrium (RA), right ventricle $(\mathrm{RV})$, and main, right and left pulmonary arteries (MPA, RPA, and LPA) using 3D radially-undersampled, 4D flow-sensitive MRI.

\section{Methods}

This HIPAA-compliant study was performed in 11 patients with TOF $(5 \mathrm{M} / 6 \mathrm{~F} ; 20.1 \pm 12.4$ years $)$ on $1.5 \mathrm{~T}$ and 3.0T clinical systems (GE Healthcare, Waukesha, WI) after IRB-approval and obtaining consent. 4D flowsensitive MRI data were acquired with a radially undersampled phase contrast (PC) sequence, PC VIPR [2] with: $320 \mathrm{~mm}^{3}$ volume, $1.0-1.25 \mathrm{~mm}^{3}$ acquired isotropic spatial resolution, and VENC of $50-200 \mathrm{~cm} / \mathrm{s}$. Scan time was approximately $8-12 \mathrm{~min}$ using an adaptive respiratory bellows reading and 50\% efficiency. Retrospective ECG-triggered cardiac gating was used with datasets reconstructed into 20 time frames. Flow visualization and analysis (Table 1) was performed using Ensight

University of Wisconsin, Madison, WI, USA

\begin{tabular}{|c|c|c|}
\hline \multirow[t]{2}{*}{ SVC/IVC } & 1 & S wave $>$ D wave \\
\hline & 2 & D wave $>S$ wave \\
\hline \multirow[t]{2}{*}{ RA } & 1 & normal, single clockwise vortex \\
\hline & 2 & increased vortices \\
\hline \multirow[t]{2}{*}{ RV diastole } & 1 & normal right-handed helix through $\pi$ \\
\hline & 2 & increased helicity and vorticity \\
\hline \multirow[t]{2}{*}{ RV systole } & 1 & uniform, laminar flow toward RVOT \\
\hline & 2 & non-uniform outflow \\
\hline \multirow[t]{2}{*}{ MPA/RPA/LPA } & 1 & uniform, laminar flow \\
\hline & 2 & helical or vortical flow \\
\hline
\end{tabular}

(CEI, Apex, NC) with particle trace emitter planes placed in SVC, IVC, tricuspid valve, and MPA.

\section{Results}

SVC and IVC flow was greater during diastole than systole in 8/11. Increased RA vortices were present in $7 / 11$. RV diastolic flow was normal in 1/11. RV systolic flow was normal in 9/11. MPA, RPA, and LPA flow was helical or vortical in $6 / 11,10 / 11$, and $10 / 11$, respectively. PR and PS were present in 10/11 and 6/11, respectively.

\section{Conclusions}

Flow patterns in the right heart of patients with repaired TOF are altered compared to previously reported flow patterns in normal subjects [3],[4]. These alterations may help explain the increased symptoms during exercise in the repaired heart. An additional benefit of acquiring 4D flow-sensitive MRI data is that flow analysis can be performed post priori through any area of interest.

\section{() Biomed Central}

(c) 2011 Francois et al; licensee BioMed Central Ltd. This is an open access article distributed under the terms of the Creative Commons Attribution License (http://creativecommons.org/licenses/by/2.0), which permits unrestricted use, distribution, and reproduction in any medium, provided the original work is properly cited. 


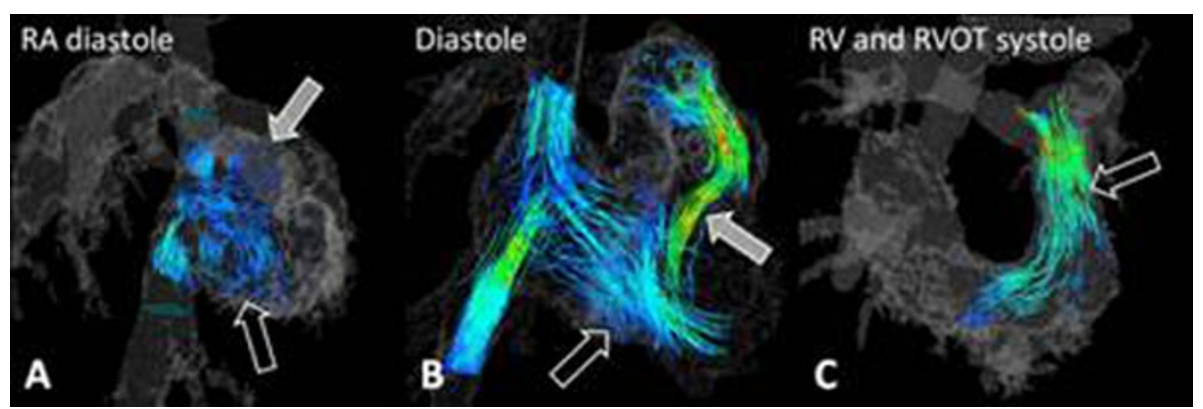

Figure 1 Right atrial and ventricular particle tracings. (A) A second RA vortex (closed arrow) was present during diastole in 7/11. (B) RV inflow was directed toward the RV apex (open arrow) in patients with PR (closed arrow). (C) RV outflow was normal in 9/11.

Published: 2 February 2011

\section{References}

1. Markl M: JCAT 2004

2. GU T: AJNR 2005.

3. Kilner PJ: Nature 2000.

4. Markl M: Eur J Cardiothorac Surg 2010.

doi:10.1186/1532-429X-13-S1-P206

Cite this article as: Francois et al: Analysis of right heart flow patterns

in repaired Tetralogy of Fallot with 4D flow-sensitive MRI. Journal of

Cardiovascular Magnetic Resonance 2011 13(Suppl 1):P206.

Submit your next manuscript to BioMed Central and take full advantage of:

- Convenient online submission

- Thorough peer review

- No space constraints or color figure charges

- Immediate publication on acceptance

- Inclusion in PubMed, CAS, Scopus and Google Scholar

- Research which is freely available for redistribution

Submit your manuscript at www.biomedcentral.com/submit
Ciomed Central 